Federal Reserve Bank of Minneapolis

Research Department Staff Report 347

October 2004

\title{
Rent-Seeking and Innovation
}

\author{
Michele Boldrin* \\ Federal Reserve Bank of Minneapolis \\ and University of Minnesota
}

David K. Levine*

University of California, Los Angeles

\begin{abstract}
Innovations and their adoption are the keys to growth and development. Innovations are less socially useful, but more profitable for the innovator, when they are adopted slowly and the innovator remains a monopolist. For this reason, rent-seeking, both public and private, plays an important role in determining the social usefulness of innovations. This paper examines the political economy of intellectual property, analyzing the trade-off between private and public rent-seeking. While it is true in principle that public rent-seeking may be a substitute for private rent-seeking, it is not true that this results always either in less private rent-seeking or in a welfare improvement. When the public sector itself is selfish and behaves rationally, we may experience the worst of public and private rent-seeking together.
\end{abstract}

*Both authors thank the National Science Foundation and Boldrin thanks the University of Minnesota Grants in Aid Program, and the BEC2002-04294-C02-01 project for financial support. We are grateful to Hugo Hopenhayn and Galina Vereshchagina and other Carnegie-Rochester seminar participants for helpful comments. The views expressed herein are those of the authors and not necessarily those of the Federal Reserve Bank of Minneapolis or the Federal Reserve System. 


\section{Introduction}

In the pursuit of profits, economic agents, be they large firms or single individuals, seek to gain an advantage over direct competitors by introducing new goods, services, and technologies. This leads to continuous adoption of innovations, which are widely recognized as the key to growth and development. Innovating is therefore a socially valuable activity, and a classical example of the way in which the selfish pursuit of the private interest may lead to increased social welfare when channeled through properly organized markets. The private advantage, though, is greatly magnified when the innovator is the sole supplier of the new good, service, or process; everybody loves to be a monopolist, and innovators are no exception to this rule. The felicitous coincidence of private and public interest breaks down here, as social welfare is generally harmed by the presence of monopolies.

Remaining, or becoming, a monopolist requires special skills and abundant resources. Often, such skills and resources allow one to stay ahead through relentless innovation. Not less often, though, abundant skills and resources are invested in keeping the competitive advantage by turning the innovation into a monopoly, either through various forms of legal exclusion, or by making it very hard for competitors to imitate 
and reproduce the good. ${ }^{1}$ We call this activity "rent-seeking". At the core of this paper is the observation that "A monopoly granted either to an individual or to a trading company has the same effect as a secret in trade or manufacturers." [Adam Smith, The Wealth of Nations, I.vii.26]. The efforts to grab either a granted monopoly, or a trade secret we call, respectively, public and private rent-seeking.

A crucial question in current and past debates on innovation is the role of intellectual property - especially patents - in fostering innovations and their adoption. Whether intellectual property increases or decreases innovation is uncertain. There are two main arguments in favor of intellectual property. The first is that without the benefit of a government monopoly, on account of increasing returns to scale, innovations would either not be produced at all or too few innovations would be produced. In Boldrin and Levine [1999, 2002] we showed that even in the absence of legal protection some, possibly most, innovations would be produced, so that at least there is a cost benefit trade-off between the deadweight loss of monopoly and the extra innovation that it would produce. However, we also showed that since

\footnotetext{
${ }^{1}$ Sometimes the instruments used to maintain exclusivity are rather extreme. The Astronomical Clock on the Old Town Hall of Prague dates back to 1410 and, so the story goes, the city had its manufacturer, Mikulas of Kadan, blinded once the clock was completed to make sure copies could not be made for other cities.
} 
innovations require earlier innovations as input, it is far from certain that government grants of monopoly actually increase innovation - they may well lead to less innovation. Neither the industrial organization nor the growth literatures have provided much in the way of empirical evidence about these effects; the debate remains therefore wide open on the role that patent protection plays in fostering innovations, their adoption and continuing economic progress.

There is however, a second argument in favor of intellectual property. This correctly observes that rent-seeking is possible through the private sector as well as the public, and that legal grants of monopoly may mitigate the costs of private rent-seeking. This may well be possible. However, what is certain is that one of the strongest arguments against existing intellectual property law is that it encourages socially wasteful rent-seeking and regulative capture in the public sector. This phenomenon has been largely ignored by economists. Here we begin to remedy that gap by examining the political economy of intellectual property and asking whether allowing public rent-seeking really leads to a welfare improvement because of the consequent reduction in private rent-seeking. 
That public rent-seeking plays an important role in the acquisition of intellectual property is clear. The recent Sonny Bono copyright extension law is a good case in point: the U.S. Congress unanimously on a voice vote extended copyright retroactively by 20 years - yet there is no economic argument whatsoever in favor of retroactive extension of intellectual property. Surprisingly, a U.S. Supreme Court that has paid strong lip-service to the principle that the original language of the Constitution matters upheld this extension in the Eldred Case, in the face of clear language that Congress can grant copyright for only a limited time. Other examples of public rent-seeking abound: in 1984 the pharmaceutical industry was given extended patent protection, in 1994 the term for all utility patents was extended from 17 to 20 years. In one of the most dramatic examples of judicial legislation, the courts enormously extended the range of patent protection to include "business practices" in 1998. During the Reagan administration, the patent examination system was reformed to make it possible to patent even the vaguest of claims. Various legal devices, such as the "submarine patent" are used to extend the length of protection, and patenting of the well-known and obvious has become widely used to "greenmail" firms into paying licensing fees. In the international arena, the U.S. has 
fought long and hard to force other countries to conform - retroactively - to our patent and copyright law.

While there are clear social dangers of allowing the government to grant monopolies, ranging from the ease with which they can be concealed from public scrutiny, to the corruption of the political system, as we pointed out at the start, rent-seeking is possible in the private markets too. Hence the view that patents are a socially valuable substitute for trade-secrecy. Granting a legal monopoly in exchange for revealing the "secret" of the innovation is one, apparently clean, way to make innovations more widely available in the long run. However, this argument has not been subject to much scrutiny by economists, and indeed, in the simplest case it fails. Suppose that each innovation can be kept secret for some period of time, with the actual length varying from innovation to innovation, and that the length of legal patent protection is 20 years. Then the innovator will choose secrecy in those cases where it is possible to keep the secret for longer than 20 years, and choose patent protection in those cases where the secret can be kept only for less than 20 years. In this case, patent protection has a socially damaging effect. Secrets that can be kept for more than 20 years are still kept for the maximum length of time, while those that without patent would have been kept for a shorter time are now 
maintained for at least 20 years. Indeed, it is important to realize that outside the pharmaceutical industry, where the regulatory system effectively forces revelation in any case, trade secrecy is considerably more important than patent. Indeed, in a survey of R\&D lab managers for processes, only $23 \%$ indicate that patents are effective as a means of appropriating returns, and for products only $35 \%$ indicate that patents are effective. By way of contrast, $51 \%$ argue that trade-secrecy is effective in both cases. ${ }^{2}$

Although in the simplest case, patent law does not impact on tradesecrecy, in cases where it is possible to expend real resources in making the secret less accessible, the innovator faces a real trade-off between private and public rent-seeking. The goal of this paper is to examine that trade-off and establish when patents may and may not yield an efficiency gain. This efficiency gain may have two sources. First, private rent-seeking may imply a higher social cost than public rent-seeking; in this case social efficiency demands a legal monopoly on account of the large social costs induced by private individuals pursuing trade and industrial secrecy. Second, the pursuit of trade and industrial secrecy may lead the innovator to restrain production of the new good even more than a legal monopolist would, thereby imposing a larger

\footnotetext{
${ }^{2}$ Cohen et al. [2002].
} 
dead-weight loss upon consumers; in this case the concession of a legal monopoly leads the innovator to safely expand capacity and allow for a more rapid adoption of the good. Our analysis shows that both these elements are indeed at play in a fairly simple and natural model of private and public rent-seeking.

Our major new finding is that there may be greater secrecy with intellectual property than without it. The public rent-seeking option has positive value only after a certain critical level of productive capacity is accumulated. Hence, an innovator that has purchased the option has an incentive to keep the secrecy until that level of capacity is reached, which can be achieved by investing substantially in the private rentseeking effort. We show that this complementarity between public and private rent-seeking may lead to higher expenditure on private rentseeking when the public rent-seeking option is available than when it is not. There are many historical examples suggesting that this kind of interplay between the private and the public channel to rent-seeking may be a relevant source of social inefficiencies. A particularly startling example ${ }^{3}$ comes from the agricultural sector. Since the beginning

\footnotetext{
${ }^{3}$ Thanks to Julio Barragan Arce, a Ph.D. student at the University of Minnesota, for teaching us these facts.
} 
of the XIX century, when the production of new seed and plant varieties took a central place in the development of modern agriculture, and until the 1960s, many new seeds were introduced but very few if any were patented and enjoyed legal monopoly protection. The reason for this was relatively simple: new seeds were technically not patentable because seeds coming from natural reproduction could not be distinguished from those coming from plant breeders (the same did apply, and apparently still applies, to cattle). This state of affairs continued until during the 1940s, after 50 years of research and thanks to a lot of private and public research money, the hybridization technique became available. To make a long story short, this technique allows for the production of patentable seeds, as the hybrid seeds cannot be reproduced (they are sterile), and only people that control the original pure kinds of seeds can produce the hybrid through a monitorable fertilization technique. From then on, lobbying from companies producing hybrid seeds for new and special legislation for plant patents intensified, and in 1960 the Plant Varieties Protection Act was enacted. This is the most stringent patent legislation for agricultural products in the whole world; it is this legislation that USA chemical monopolies are trying to impose on the agricultural sectors of less developed economies. Hybrid seeds, which cost billions of private and public dollars to 
be developed, are neither particularly more productive nor socially (as opposed to privately) valuable than traditional ones. They are, instead, patentable, which allows their producers to establish and maintain a monopoly power. Notice, in particular, that if the option of eventually purchasing patents for the hybrid seeds had not been available, resources would not have been wasted in the first place to develop the hybridization technique. This is a good example of socially damaging reinforcement between private and public rent-seeking.

This interaction is a natural outcome of our model, but goes dramatically against established wisdom. It shows that the idea of a beneficial trade-off between the two kinds of rent-seeking activities may well be an illusion, thereby bringing the theory closer to the facts of life. We prove that such a perverse effect is always at play when the private cost of public rent-seeking is relatively high; in particular, when the cost of public rent-seeking is so high that an innovator is indifferent between purchasing or not purchasing the public monopoly option. One may therefore be led to conclude that all that is needed is a benevolent social planner setting the cost of public rent-seeking low enough to make this perverse effect vanish. This is correct: all that is needed is a benevolent social planner, if we had one. The usual perspective is one in which the government can perfectly commit to a socially efficient 
mechanism. In practice, governments committing to socially efficient mechanisms are less common than complete contingent markets. As we briefly reminded above, in reality we observe that, through a process of "regulatory capture", governments eventually become part of the overall rent-seeking system. We examine the latter perspective in our final section where we endogenize the cost of obtaining a patent. Here we are looking at the polar opposite of the usual case; in the usual case commitment is complete and institutions function perfectly; when the government is rent-seeking, institutions do not function in the social interest. We show that this has potentially devastating consequences for innovation and welfare. The rent-seeking regulator will set the cost of public monopoly near the level at which the innovator becomes indifferent between exercising or not the public monopoly option. At this level, as we just argued, the level of expenditure in private rentseeking activities is maximized. This leaves the question of the extent to which institutional commitment is possible. We think that a complete absence of patent rights can be institutionally committed. It is, for example, easily verifiable, which increases the chances of sticking to the commitment. We suspect that anything less is likely to be subverted, as witnessed by the many examples of rent-seeking extensions of intellectual property law cited above. 
Related Literature. Little has been written about the trade-off between secrecy and public rent-seeking beyond the bland and incorrect assertion that patents lead to revelation of secrets that would not otherwise be revealed. There is a small literature that focuses on the information revelation process that occurs during patenting (Anton and Yao [2000]) and on its role in patent races (Battacharya and Ritter [1983)], Horstmann, MacDonald and Slivinski [1985]). Okuno-Fujiwara et al. [1990] examine how disclosing information that changes beliefs may work to a firm's advantage. Ponce [2003] considers the possibility that by disclosing a secret, a rival might be prevented from patenting the idea. This leads to the possibility that secrecy may actually increase with patent protection. We should note also that this literature usually focuses on oligopoly, assumes there are no costs in public rent-seeking and does not consider the issue of timing. The political economy of intellectual property law has been even less well examined. Scotchmer [2002] examines the political economy of patent treaties an important topic, but not one directly related to the issue of public versus private rent-seeking.

From a broader perspective we are also interested in the utilization of patents over the life-cycle of industry. Our intuition based on industry case studies is that they play a relatively unimportant role in the early 
life of the industry when demand is still quite elastic and the number of entrepreneurs is very large. It is in the mature stage where demand is inelastic, few firms are either around or entering, and returns on innovative efforts are low, that the competition for innovation ceases and the competition for government grants of monopoly begins. The computer software industry seems like a case in point, with legal action taking center stage only as the industry matured, and Microsoft gained substantial monopoly power, while the innovation rate stagnated or even declined in spite of the stronger legal protection awarded to IP. ${ }^{4}$ As a first step, we focus here on the optimal timing of protection for a single innovator, establishing that it is later rather than earlier in the product life-cycle that patent protection is worth paying for. In other words, here we concentrate only on the impact of demand elasticity on public rent seeking. In particular, we do not consider the fact, especially important in early stages of an industry, that innovations build on each other. As many authors have pointed out, see Scotchmer [1991], Boldrin and Levine [1997, 1999], and Bessen and Maskin [2000], for example, patents are especially costly in this context.

In understanding this paper, it is useful to begin by asking what positive role can patents and other forms of intellectual property (IP)

\footnotetext{
${ }^{4}$ As documented, among others, by Bessen and Maskin [2000].
} 
have. On the one hand, when the sole innovator has no access to the secrecy-keeping technology, then either imitation or market acquisition of the new technology leads to expansion of productive capacity, competition, and efficiency. On the other hand, when many individuals innovate simultaneously the minimum size restriction typical of innovation must not be binding, in which case, again, an environment without monopoly rights maximizes social welfare. The presence or absence of a secrecy enhancing technology is irrelevant in such circumstances, as nobody has any incentive to use it. This much we have shown in Boldrin and Levine [1997, 1999, 2002], where some of the social costs of allowing for patents, copyrights, and other forms of IP in the environments just illustrated are documented. A corollary of our argument is that reverse engineering, if it takes place in competitive markets, is socially beneficial even when it involves a set-up cost. This follows from the observation that reverse engineering is just another means of expanding productive capacity for the new good. Under perfect competition, if it is profitable to use it to expand capacity, then it is also socially useful. This observation rids us of one of the most frequently abused arguments supporting IP, and patents in particular: that patents, by forcing the disclosure of the innovative secret, avoid the socially wasteful "rediscovery" of the same idea by future imitators. This argument 
relies either on the existence of some negative external effect, whose nature is obscure to us, or on the assumption that pure or disembodied "ideas" have economic and productive value, which is patently false.

If patents, though, are necessary neither to induce innovation (when competitive rents provide plenty of incentives), nor to avoid "wasteful rediscovery" (when reverse engineering is socially valuable) then: what are patents good for? The answer must be found in a situation where there is not a great deal of simultaneous innovation, the ideas that are patented cannot lead to further valuable innovation, and private secrecy is effectively enforceable. In this case IP may serve two purposes. First, it may serve to increase the incentive to innovate in the presence of fixed costs. This idea has been extensively examined, and we will not re-examine it here. Second it may help avoid wasteful expenses in private secrecy, which we call here "private rent-seeking." Consider, for instance, the case in which private investment in secrecy is effective because it reduces the risk of being imitated, but has substantial social cost. In this case it is possible that "public rent-seeking" in the form of publicly enforced IP may be a cost effective replacement for private secrecy. This tradeoff between the social costs of private and public rent-seeking is at the heart of this paper. 


\section{THe MOdeL}

As indicated, our focus is not on the role of intellectual property in promoting innovation, but rather on the impact that the substitutability between private and public rent-seeking may have on the rate of adoption of innovations, and on the IP policies that optimize social welfare. For this reason we shall examine the case of a single innovator, who has already produced an innovation and, at a private cost, can reduce the chances that others may imitate his product. We make the twin assumptions that the innovator starts out as a natural monopolist, and has access to a private technology to enhance secrecy, because, as we have argued, these are the circumstances in which a publicly enforced system of IP may serve a beneficial purpose.

Three observations about innovation are captured in our model. First, it takes time to ramp up productive capacity for a new product. Second, in the absence of legal protection it is possible for the innovator to achieve a degree of monopoly through secrecy; such degree of secrecy varies from innovation to innovation. Third, ideas are useful only insofar as they are embodied in either people or things, hence the leaking of industrial secrets about innovation has an impact only insofar as the secrets are embodied in new productive capacity. 
Our perspective is one in which making copies of the new good requires productive capacity. We model productive capacity by merging two ingredients, capital (either physical or human, as we will see momentarily) and the secret, or idea. It is useful to think of two polar cases. In the first case, the entire idea behind the new product is embodied in a particular type of machine. By building the machines himself and exercising physical control over them, the innovator can attempt to retain his monopoly power over the new idea. ${ }^{5}$ In this case, productive capacity is equal to the number of existing machines, which grows only if the owner of machines allows them to grow. Further, whatever is valuable in the innovation is embodied in the machines. Eventually, due to some random event, the secret may escape the innovator's control. In this case monopoly power is not lost as all productive capacity is still in the hands of the initial innovator. Because of this, he is still a monopolist, at most facing a competitive fringe. This

\footnotetext{
${ }^{5}$ Or at least until the innovation is independently discovered. As mentioned, we will not examine the possibility of independent inventions in this paper; while patents can be and are used to hinder independent discovery, the economic rationale supporting this is quite weak. As we have argued, in the absence of patents, simultaneous discovery can be an efficient event which increases productive capacity and social welfare. Scotchmer [1991] also makes the case that IP protection should not be strong in the face of independent discovery.
} 
we call the Coca-Cola case. At the opposite extreme, almost everything that is valuable in the idea is embodied in the human capital of each worker hired and trained by the innovator. The innovator, nevertheless, does retain the "last piece of the puzzle", which is necessary to turn workers into productive capacity. When this last piece is revealed, again due to a random event, any and all workers may independently start production of the final good. Hence, in this second case productive capacity is the number of trained workers. The latter is controlled by the innovator until a random event reveals the secret to the workers. After the random event, the innovator must compete with his own workers. This we call the Napster case, because, after the secret is revealed, it is functionally equivalent to the model studied in Boldrin and Levine [1999]. We describe that model here briefly, to provide an additional interpretation of the formalism adopted and facilitate later references to results. In that model the valuable idea is completely contained in the final good (a CD) which is durable. Anyone who has purchased the CD can easily see how it is made, and produce their own copies. Productive capacity corresponds to the cumulated number of copies of the $\mathrm{CD}$, as the remaining inputs needed to copy are available to anyone at competitive prices. In this case secrecy is impossible (as the aforementioned "last piece of the puzzle" is absent) and, barring 
legal restrictions, the innovator is in direct competition with his customers as soon as he makes a sale. Hence, capacity grows over time as additional copies are made and sold, and competition reigns from the outset.

Our model will allow these two extremes, as well as intermediate cases. Specifically, if the "last piece of the puzzle" becomes known when productive capacity is $k$ we assume that a fraction of capacity $\alpha$ remains in the hands of the original innovator, with the remaining fraction $1-\alpha$ falling into the hands of competitors. In the Napster case, $\alpha=0$ while in the Coca-Cola case $\alpha=1$. Note that we assume that the "last piece of the puzzle" follows the traditional model of diffusion of ideas - once revealed, it spreads instantaneously and costlessly. It is a striking fact that even if a large portion of the idea is immune from the costs ordinarily associated with information transmission, the fact that a remaining portion of the idea is subject to the ordinary constraints of scarcity is enough to enable the originator of the idea to obtain the full competitive rent in the form of the present value of all downstream profits generated by the original idea.

2.1. Production and Consumption. Producing consumption requires two ingredients, capital, and the secret needed for turning capital into productive capacity. As noted, in the Coca-Cola case the secret is 
completely embodied in the machines. Once you get your hands on one machine you control its secret; as machines reproduce themselves, owners of machines control productive capacity and its growth rate. In the Napster case the secret is embodied in workers, minus the little detail controlled by the innovator. As long as workers work for the innovator, they constitute productive capacity. When working independently, they are completely unproductive until the secret is revealed. In both cases we denote productive capacity by $k$. Initial capacity, held by the sole innovator, is $k_{0}$. To simplify computations we adopt a continuous time model, and assume the real interest rate $r$ is fixed. We adopt the simplest formalism for increasing capacity over time: as in Quah's [2002] 24/7 model, or in a learning by doing model, capacity grows at $\dot{k} \leq \gamma k$, with equality unless the owner of $k$ exercises his power to freely dispose of capacity. ${ }^{6}$

Productive capacity produces consumption. The flow of consumption is $c(t) \leq k(t)$, with equality holding unless the owner of the stock of capacity elects to withdraw some from production. There is a single

\footnotetext{
${ }^{6}$ In what follows we assume this growth rate to be independent of how many people are privy to the secret. The maximum growth rate of capacity is likely to increase when the secret is revealed. In this case some of our results are strengthened, as we note when relevant.
} 
representative consumer with quasi-linear utility

$$
U=r \int_{t=0}^{\infty} u(c(t)) e^{-r t} d t+m
$$

where $m$ is the numeraire good. In addition to productive capacity, consumption may need other resources to produce. We assume that this industry is small, so that the other resources are obtained at the fixed price $w$. Hence, the instantaneous cost of producing $c$ units of consumption is $w c$. Concerning utility and cost, we assume

Assumption 2.1. $u(c)$ is thrice continuously differentiable, and $u^{\prime}(0)>$ $w$.

We can then define instantaneous profits $\pi(c)=\max \left\{0, u^{\prime}(c) c-w c\right\}$. We assume that these are well-behaved in the following sense Assumption 2.2. $\pi(c)$ is single peaked, with a maximum at $c=M$.

For future reference, let $C>0$ denote the value of output at which $\pi(C)=0$.

2.2. Monopoly and Competition. We assume that the innovator's objective is the average present value of profits. Consider first the case in which the innovator has a complete monopoly, that is: he controls all productive capacity from beginning to end. This corresponds to the 
case of $\alpha=1$. The average present value of profits is $r \int_{0}^{\infty} e^{-r t} \pi(c(t)) d t$. Facing a capacity constraint that grows at a constant rate, and a singlepeaked profit function, the optimal plan for the monopolist is clear enough: allow capacity to grow as rapidly as possible until the profit maximum is reached at $k=M$, then stop investing, and leave capacity fixed at $M$. Let $s=(1 / \gamma) \log \left(M / k_{0}\right)$ denote the time at which $k(s)=$ $k_{0} e^{\gamma s}=M$. Note, for future use, that the "time to the profit maximum" $s$ is a function of the initial condition $k_{0}$, even if we often omit it. Write

$$
R_{1}(k)=r \int_{0}^{s} e^{-r t} \pi\left(k e^{\gamma t}\right) d t+(k / M)^{r / \gamma} \pi(M)
$$

for the average present value of profits accruing to this plan beginning with an initial capital stock of $k$. It is straightforward to see that, in light of our assumption about $\pi$, the function $R_{1}(k)$ is maximized when the initial condition satisfies $k=M$.

Consider next the case in which there is complete competition. Here the innovator controls a negligible share of total productive capacity, that is: $\alpha=0$, and he is in direct competition with the imitators. Since, even in this case, every available piece of productive capacity must derive from the original unit held by the innovator, and since imitators compete with each other bidding their own profits to zero, as in Boldrin and Levine [1999], the innovator still earns the competitive 
rent, which is the average present value of profits. However, contrary to the previous case, the growth of productive capacity is out of the control of the innovator; competition between many producers leads capacity to expand at the greatest possible rate, and output to expand to the point at which profits fall to zero. So the competitive rent, starting from an initial capital stock of $k$ is

$$
R_{0}(k)=r \int_{0}^{\infty} e^{-r t} \pi\left(k e^{\gamma t}\right) d t
$$

Recall that we have defined profits to be zero when capacity is such that marginal cost would exceed price, that is, when productive capacity is larger than $C$. We show in Lemma A.2 of Appendix A that $R_{0}(k)$ is maximized at a stock of capital $M_{0}<M$. The subscripts zero and one in $R_{0}(k), R_{1}(k)$ are meant to remind us that $\alpha=0, \alpha=1$, respectively, hold here; later on we will introduce the function, $R_{\alpha}(k)$, for the general case of $0 \leq \alpha \leq 1$. This has a maximizer $M_{0} \leq M_{\alpha} \leq M_{1}=M$, which by Lemma A.2 is shown to be strictly increasing in $\alpha \in[0,1]$.

It is interesting to examine the difference between monopoly profits and competitive rents, $R_{1}(k)-R_{0}(k)$. Recall that $e^{-r s}=\left(k_{0} / M\right)^{r / \gamma}$, and that in both cases, capacity, and hence profits, grows as quickly as possible until the profit maximum is reached at $M$. Hence the difference between monopoly profits and competitive rents is simply 
their difference at $M$ discounted by the time it takes to reach $M$.

$$
R_{1}(k)-R_{0}(k)=(k / M)^{r / \gamma}\left(\pi(M)-R_{0}(M)\right) .
$$

This is an increasing function of $k$ : the higher initial productive capacity is, the stronger the incentive to retain monopoly power. The key observation from comparing monopoly and competition is that both competitive rents and monopoly profits constitute the present value of a future profit stream: the benefit of monopoly is that it makes it possible to keep capacity from expanding beyond $M$, thereby keeping profits at their maximum forever.

Two additional remarks. Neither the value of $R_{1}(k)$ nor that of $R_{0}(k)$ depend on the probability of losing the secret, because in the first case the secret is, from a practical point of view, never lost, while in the second it is lost immediately. Suppose the stock of capital at the time the secret is lost is $k$. By analogy, then, we will also define $R_{\alpha}(k)$ for values of $\alpha \in(0,1)$ as a function of the stock $k$ when the secret is lost. This will facilitate comparison and computations in the subsequent analysis.

2.3. Rent-Seeking. Our goal is to consider the implications of allowing rent-seeking behavior. We now assume the innovator faces the risk of his secret leaking out, which, in conjunction with the reproducibility 
of the stock of capital, would force him to face competition in subsequent periods. This possibility induces rent-seeking by the innovator, who would like to behave like a monopolist by controlling capacity. He can do so privately, by keeping key ideas surrounding the innovation secret and by designing the product to make reverse engineering difficult. However, once the secret leaks out, it cannot be made unsecret. Thus, our model of private rent-seeking is one in which the innovator chooses an effort level of $a$ to keep the secret. We let $a$ be the up-front cost; there may also be an ongoing cost, including the possibility that making the product less easy to reverse engineer makes it less useful to consumers. An example would be crops that are genetically engineered to be sterile, thereby preventing farmers from reproducing them. As long as the innovator must commit at the initial time to a particular level of ongoing cost, we may capitalize the expected present value of this cost into the initial up-front cost $a$, so the only loss in generality is that we do not consider the possibility that the ongoing cost may be endogenously chosen to be time-dependent. Given the effort level measured by $a$, there is a chance that the secret is lost. This occurs according to a Poisson process with intensity parameter $\lambda(a) .{ }^{7}$ Naturally, $\lambda$ is decreasing in $a$; assume this occurs at a decreasing rate. It

\footnotetext{
${ }^{7}$ Little of substance would change if it were made to depend also upon current or cumulated output. It would only increase the incentive to reduce capacity and
} 
is natural to think of the secret being lost through reverse engineering (either on the product in the Coca-Cola case, or by workers in the Napster case) and the success of the reverse engineering to depend on the effort made to acquire the secret. We do not explicitly model the reverse engineering effort, treating it as exogenous. Notice, however, that the cost of reverse engineering will be accounted for in the price paid to acquire the product. Keeping secrecy by means of this kind of $a$ effort, we call private rent-seeking.

We wish also to consider the possibility of public rent-seeking, that is rent-seeking through the legal system. This rent-seeking takes place through the purchase of a legal monopoly. Since existing patent terms are quite long (20 years) we assume the monopoly lasts forever, and do not consider the question of optimal patent term. Other forms of IP, such as non-disclosure agreements may last forever anyway. To completely acquire a legal monopoly, in reality, requires potentially several costs. Initially, the innovator must pay a cost $b_{0}$. This may correspond to the need to file for patent protection as soon as possible and to the fact that non-disclosure agreements must be signed prior to revealing the good; or to other elements that might either practically

output to maintain secrecy. This we can pretend to be captured by the social cost of private rent-seeking, $w_{a}$, discussed below. 
or legally require an initial payment. Second, at some time at or before the secret is revealed and the monopoly purchased, an additional cost $b_{1}$ might be incurred. For example, it may be possible to anticipate the revelation of the secret, and take out a patent immediately before it is revealed, or purchase a submarine patent, surfacing only when the secret leaks out. In addition a third cost may be incurred every time the legal monopoly is enforced. This cost, which is not modeled here, might include, for example, the legal cost of bringing violators to court, which takes place obviously after the secret is revealed.

Monopoly power allows the innovator to control capacity. Initially, the innovator has a defacto monopoly, and chooses how much $a$ to expend, and whether or not to expend $b_{0}$. This fixes $\lambda$ the instantaneous probability of the secret leaking out. In any case, the innovator enjoys a monopoly until the Poisson event of the secret being lost occurs. Up until this time, the innovator is assumed to have complete control over capacity through his unique knowledge of the secret. If he chooses the initial expenditure of $b_{0}$ he also has the option during this period of paying $b_{1}$ and getting a legal monopoly - but since the interest rate is positive, it is better to wait. When the Poisson event occurs, if he has not done it before, and if he has made the initial expenditure $b_{0}$, the 
innovator must decide whether to expend $b_{1}$ to secure legal monopoly or not.

What happens when the secret is lost? This is potentially quite complicated. The secret, like capital, may take some time to spread. In fact, the slow speed at which ideas spread is probably one of the key empirical factors making patents and IP redundant or socially damaging in many cases. Still, given the scope of this paper, we shall simplify the analysis and stack the odds in favor of IP by considering the extreme case in which the secret spreads instantaneously once it is uncovered. Still, to take advantage of the secret requires competitors to have a stock of capital of their own. In the Napster case, the stock of capital is not controlled by the innovator, but rather by his workers or customers, who, once the secret is available, turn capital into productive capacity and become competitors. More precisely, under the interpretation of capital as the human capital of the workers, once the secret is revealed the workers set up a large number of independent and competitive firms producing the good. However, in the Coca-Cola case the productive capacity takes the form of specialized physical capital that belongs to the innovator. In this case, even if the Poisson event occurs and the secret is made public, new machines owned by the competitors will take time to build, while the innovator still retains all or 
at least a large fraction of his machines. This issue is both relevant and delicate, so we discuss it next in some detail.

To be concrete we shall assume that, after the secret is revealed only a fraction $0 \leq \alpha \leq 1$ of the capital remains with the innovator. The remainder portion of capacity $1-\alpha$ is transferred to the competitors, through means we will discuss momentarily. Due to competition, this capacity grows as quickly as feasible, that is at the rate $\gamma$. The remaining level of investment is controlled by the innovator, who, like a monopolist faced with a competitive fringe, may choose how quickly to grow his own capacity, up to the maximum growth rate of $\gamma$. Notice that faced with a competitive fringe, the innovator will wish to move towards his best response to the flow of output produced by the fringe firms. This will increase his own profit, but will not increase industry profits and may in fact reduce them. This would be the optimal response of the innovator after the secret is leaked, if it were not the case that, in fact, he has a vested interest in maximizing the profit level for the whole industry. The reason is simple: to the extent the innovator knows that there is a chance the secret will leak, he can act in such a way to sell part of his capacity to competitors before the event leaks. This can be done in a variety of ways, for example, by selling the goods 
themselves (the Napster case of Boldrin and Levine [1999]), by training workers at an implicit fee deducted from their wages (the Napster case when capital is human capital), via profit sharing agreements, by sale of parts of the equipment not carrying the secret, or by a variety of contingent contracts. The key point is that the price at which the innovator can sell his capacity depends on industry profits after the secret leaks out. In other words, before the secret leaks out, the innovator has an incentive to commit to maximizing industry profits after the secret leaks, because this choice maximizes the prices at which he can sell capacity. This commitment problem, however, is easily solved. The innovator would like to commit to keeping industry output high, and not lowering towards his best-response. The commitment can be as simple as selling advance orders. These advance orders can be contingent on when the secret is revealed, and whether he chooses to use the option of a public monopoly, but we will see later that the optimal plan in these contingencies is consistent with honoring the advance orders anyway, so he need not do so. Our assumption, then, is that through precommitment, if the innovator chooses not to use the option of public monopoly, he chooses his output after the secret leaks out to maximize industry profit. 
2.4. An Example. It is useful to have a concrete example of how this model works. We adopt the following example from an episode of the television series The Simpsons. Let us imagine a good that is an alcoholic beverage called a "flaming Moe" made from Tequila, Schnapps, Crème de Menthe, and the secret ingredient: Krusty Non-Narkotik Kough Syrup. ${ }^{8}$ To produce this beverage requires careful combination of the ingredients. The stock of productive capital is represented by skilled bartenders who are trained to carry out this elaborate process. However, only Moe, the innovator, knows that the "missing piece of the puzzle" is Krusty Non-Narkotik Kough Syrup. The bartenders do not know what it is, and Moe adds the secret ingredient at the end. Each bartender requires an assistant, and after some period of time, the assistant becomes trained. Initially Moe hires an assistant, and the two of them produce some small amount of the compound. Once the assistant is trained, they acquire two assistants, one for each, and productive capacity expands in a series of franchises. At some point, the secret leaks out - and word quickly spreads that the secret ingredient is Krusty Non-Narkotik Kough Syrup. At this point, the bartenders no longer need to work for Moe, and all start production on their own; in this case $\alpha=0$. While it might seem that all is lost to Moe at

\footnotetext{
${ }^{8}$ We are grateful to Sami Dahklia for bringing this example to our attention.
} 
this point; in fact, this is not true. In addition to the profit he earned prior to the revelation of the secret, he can still lay claim to the entire expected average present value of profits his workers will make on their own once the secret is revealed. This is because he can charge the employees for the knowledge that will, once the secret is revealed, become useful to them. Competition among potential employees will reduce their profits to zero. Notice that this second source of revenues for the innovator must be computed as an expected value: when he hires the first assistant the latter faces an expected arrival time of the Poisson event, which will make her an independent producer. The innovator will charge her for the expected value of the profits she will make after she opens up shop. Such expected value, clearly, depends on the expected arrival date of the Poisson event. As Becker [1971] says, "Firms introducing innovations are alleged to be forced to share their knowledge with competitors through the bidding away of employees who are privy to their secrets. This may well be a common practice, but if employees benefit from access to salable information about secrets, they would be willing to work more cheaply than otherwise." Notice, though, that since the innovator has the option of purchasing a legal monopoly, employees will insist on a contract in which they are reimbursed by the 
innovator if he chooses to purchase the monopoly. Monopolistic firms do tend to be particularly generous with their employees.

In our model then, even if both private and public rent-seeking opportunities are absent, the innovator is still holding claim to the entire stream of profits. Assume, in fact, that the probability of the secret leaking out is exogenous and that, once the secret is revealed, the whole industry goes competitive instantaneously. Still, when introducing the new good our hero looks forward to earning monopoly profits until the secret is revealed, plus the whole competitive rents earned by the industry from this time onward. To the extent he retains a fraction $\alpha>0$ of total productive capacity after the secret leaks, he can do better than that. He can commit to the following strategy: once the secret leaks and a portion $(1-\alpha)$ of the industry goes competitive, thereby growing at a rate $\gamma$, the innovator can let the total productive capacity grow until the industry's profit maximum of $M$ is reached, then maintain it at $M$ for a finite amount of time, by letting his own share $\alpha$ of productive capacity shrink to zero. We call these two periods of time $s$ and $s^{\prime}$, respectively. We have already computed $s ; s^{\prime}$ is computed in Lemma A.1 of the Appendix. The monopoly profits accruing to the industry 
during the time period $s^{\prime}$ will go to the innovator himself, as the competitors bid their own rents to zero when purchasing their initial stock of capital from him.

2.5. Costs of Rent-Seeking. In practice there are many ways of maintaining a monopoly. Technical means revolve around secrecy, but secrecy may also be enforced legally through employment contracts, disclosure agreements, no-compete clauses and other forms of downstream licensing. Alternatively, a patent provides a legal entitlement to a monopoly. Our distinction between private $(a)$ and public rentseeking $\left(b=\left(b_{0}, b_{1}\right)\right)$ is roughly that between technical means that do not require government enforcement (besides preventing theft) and government enforcement itself. The former can range from developing a product that is difficult to reverse engineer, employing safes and private security guards, and introducing compensation schemes that give key employees an incentive to keep the secret by giving them a share of the monopoly profit. Anton and Yao [1994] give an example of such a scheme. On the other hand, government enforced monopoly, whether through outright grants as is the case with patents, or through the enforcement of downstream licensing provisions to prevent employees from competing to increase capacity beyond the monopoly level, we view as public rent-seeking. 
Both the secrecy cost $a$ and purchase price $b$ of a legal monopoly represent the private cost of rent-seeking. Each has also a social cost $w_{a}, w_{b}$. The social cost may be either greater or less than the private cost, as the effort to seek monopoly power may either lead to a waste of other social resources, or may generate some socially valuable goods. In either case, a portion of the private cost may represent a transfer payment - in the case of secrecy, the cost of an incentive scheme to encourage key employees to keep the secret; in the case of legal protection, the cost of a bribe to a public official. Another portion of the private cost may represent an allocative inefficiency, for example, costly engineering time spent to develop a product that is difficult to reverse engineer, or costly time spent by lobbyists or lawyers lobbying or litigating. In the case of secrecy, the social cost could conceivably be even negative, if a product that is difficult to reverse engineer also happens to be more useful to consumers. In the case of legal protection, the social cost includes the cost of enforcement, and this can easily exceed the private cost if the public sector provides costly enforcement services for free. This is what is envisaged, for example by the $\mathrm{SSSCA}^{9}$, and

\footnotetext{
${ }^{9}$ The SSSCA is one of several proposed bills that would mandate computer hardware in order to protect digital copyrighted material. Since the computer industry is at least an order of magnitude larger than the value of digital copyrighted material, and the cost of the mandate is to be borne entirely by that industry, the
} 
is currently a consequence in the U.S. of having a special court system for hearing patent cases. Another source of social cost that is not reflected in the price of a patent is the wasteful production of competing or preemptive patents, often aimed only at delaying or blocking a specific patent, or the distortionary incentive to produce goods that are patentable as opposed to nonpatentable, even if the former may have substantially less social value than the latter. Finally, even if obvious, we must not forget the dead-weight loss in the flow of consumer surplus brought about by the monopolist, which in this model equals

$$
\begin{gathered}
r \int_{0}^{\infty} e^{-r t} u\left(k_{0} e^{\gamma t}\right) d t-r \int_{0}^{s} e^{-r t} u\left(k_{0} e^{\gamma t}\right) d t-r \int_{s}^{\infty} e^{-r t} u(M) d t \\
=\left(k_{0} / M\right)^{r / \gamma}[U(M)-u(M)]
\end{gathered}
$$

where $U(k)=r \int_{0}^{\infty} e^{-r t} u\left(k_{0} e^{\gamma t}\right) d t$.

We are assuming that only the entrepreneur can purchase a legal monopoly. There are various reasons for this. In the model, purchasing the full legal monopoly requires having paid the entry fee $b_{0}$, a choice available only to the innovator. Even in the absence of such an entry fee, as long as he has a slight cost advantage over his employees and others who have the secret, the innovator will have an advantage in potential for social cost greatly exceeding the value of the monopoly being protected is obvious. 
bidding for the monopoly. Also, under existing law, the innovator has a legal advantage in getting a patent. We will consider in more detail below the consequences when a legal monopoly may be awarded to someone other than the innovator. Notice, finally, that in the case of simultaneous innovation, which we do not consider in this paper, innovators will be willing to expend all expected monopoly profits in the effort to grab the right to legal monopoly.

Our concern is to study the impact that the legal and institutional environment for intellectual property has on private rent-seeking activities, and the speed of innovations' diffusion. Within our framework, this means taking $b$ and $\alpha$ as policy or environmental parameters, and characterizing how the equilibrium choice of $a$ depends upon them. In the last section we also consider a number of ways in which the public rent-seeking parameters $b$ can be endogenously determined and the dramatic impact this endogenous determination may have on social welfare.

\section{Solving the Model}

We find the optimal strategy for the innovator based on the two options available at time $t=0$, pay or do not pay $b_{0}$. We call the first "IP" and the second "NIP" strategy. After characterizing the optimal 
strategy, we devote the remainder of the section to explaining the main result. Formal proofs can be found in Appendix A. We will later examine the solution from the perspective of mechanism design and social welfare, and finally consider rent-seeking by the public sector.

3.1. Optimal Strategies for an Innovator. Finding the optimal strategy involves several steps. First we must find the optimal innovator strategy after the secret is revealed. Next, we describe, for given $a$, the optimal plans for choosing capacity when, respectively, public rent seeking is not and is used. Then we solve for the optimal $a$ when $b_{0}$ is paid, $a_{i p}$, and when it is not, $a_{n i p}$, and for the decision whether or not to use the second stage of the $b$ option. Finally, we discuss the way in which private rent-seeking expenditure $a$ depends on the cost $b$ of public rent-seeking.

3.2. What to do After the Secret is Revealed. When the Poisson event occurs and the secret is revealed, an innovator who did not purchase the $b$ option at time zero faces a straightforward optimal sequence of action. He and his competitors increase capacity as quickly as possible until the industry reaches $M$. The innovator then acts to maximize industry profits. To achieve this, he must keep the industry productive capacity at $M$ for as long as possible. As his competitors continue accumulating their capital stock at the rate $\gamma$ he must reduce 
his own capacity until the latter vanishes. Once he has exhausted his capacity, the industry becomes competitive, and he earns $R_{0}(M)$ thereafter. (Recall that $R_{0}(k)$ is the competitive rent from beginning at $k$.) In Lemma A.1 we show that the net present value of being at $k$ when the Poisson event strikes, holding a share $\alpha$ of capacity, and following the strategy just described, is equal to

$$
R_{\alpha}(k)=r \int_{0}^{s} e^{-r t} \pi\left(k e^{\gamma t}\right) d t+\left(\frac{k}{M}\right)^{r / \gamma}\left[\pi(M)-(1-\alpha)^{r / \gamma}\left(\pi(M)-R_{0}(M)\right)\right]
$$

We show in Lemma A.2 that as $\gamma \rightarrow \infty$ we have $R_{\alpha}(k) \rightarrow R_{0}(k)$.

When the Poisson event occurs, an innovator who has initially chosen to pay $b_{0}$ has the option to spend $b_{1}$. If he chooses not to do so, he is left with the same continuation strategy described above. If, instead, he chooses to pay $b_{1}$ at the time the secret is revealed, he will grow capacity as quickly as possible until $M$ is reached, and then remain there forever. Recall that, after the secret is revealed, an innovator who has turned down the IP option, faces a payoff equal to $R_{\alpha}(k)$. The gain over $R_{\alpha}(k)$ from the plan that involves paying $b_{1}$ is simply

$$
\mu(k)=\left\{\begin{array}{cc}
R_{1}(k)-R_{\alpha}(k)-b_{1} & k<M \\
\pi(M)-R_{\alpha}(M)-b_{1} & k \geq M
\end{array} .\right.
$$


Notice that, depending on $k$, the function $\mu(k)$ can be either positive or negative. This means that, for a given vector $b$, the choice of exploiting or not the public rent-seeking option when the secret is revealed depends upon the stock of capital at that time.

The two sequences of actions described so far constitute the set of potentially optimal strategies once the secret is revealed.

\subsection{Two Strategies Before the Secret is Revealed, NIP and IP.}

Begin by noticing that, without costs of rent-seeking, the best strategy consists of reaching $M$ as soon as possible, and remaining there forever. Departing from such a simple accumulation strategy is optimal only when keeping the monopoly power forever becomes too costly. This leads, before monopoly is lost, to choosing a target position for capacity that is lower than $M$. This choice serves the purpose of balancing the maximization of period-profits accruing during the monopolistic phase (which would be achieved at $M$ ) with that of maximizing profits accruing after competition ensues (which, as shown by Lemma A.2 of the Appendix, is achieved at $\left.M_{\alpha}<M\right)$. Denote this interim target by $\xi_{\alpha}$. We show in Lemma A.5 that $M_{\alpha}<\xi_{\alpha}<M$.

Fix $a$ and the initial stock of capital $k_{0}$. We now define the two strategies NIP and IP, and compute the corresponding profits, gross of $a$, for each of them. 
Strategy NIP. Do not pay $b_{0}$. If $k_{0}>\xi$ reduce capacity to $\xi$; if $k_{0}<\xi$ grow capacity to $\xi$. If $\xi$ is reached before the Poisson event, stay there until the event occurs. Once the event occurs, follow the continuation path yielding $R_{\alpha}$. Profits (gross of $a$ ) from the NIP strategy are shown in Lemma A.3 of the Appendix to be

$$
\Pi_{N I P}(a, \xi)=R_{\alpha}\left(k_{0}\right)+\left(k_{0} / \xi\right)^{(\lambda(a)+r) / \gamma} \frac{r}{\lambda(a)+r}\left(\pi(\xi)-R_{\alpha}(\xi)\right) .
$$

Notice that we find $\xi_{\alpha}$ by maximizing these profits with respect to $\xi$.

Strategy IP. Pay $b_{0}$. If $k_{0}>M$ reduce capacity to $M$; if $k_{0}<M$ grow capacity to $M$. If $M$ is reached before the Poisson event, stay there; when the event occurs pay $b_{1}$. If the event occurs before $M$ is reached and $\mu(k)<0$ do not pay $b_{1}$; go instead for payoff $R_{\alpha}$. If $\mu(k) \geq 0$ when the event occurs, expend $b_{1}$ and allow capacity to grow until $M$; then remain at $M$ forever. Profits (gross of $a+b_{0}$ ) from the IP strategy are given by

$$
\begin{aligned}
\Pi_{I P}(a) & =R_{\alpha}\left(k_{0}\right)+\left(k_{0} / M\right)^{(\lambda(a)+r) / \gamma} \frac{r}{\lambda(a)+r}\left[\pi(M)-R_{\alpha}(M)\right] \\
& +\int_{0}^{\infty} \lambda(a) e^{-(\lambda(a)+r) t} \max \left\{\mu\left(k_{0} e^{\gamma t}\right), 0\right\} d t
\end{aligned}
$$

The next theorem describes the optimal strategy. 
Theorem 3.1. The optimal innovator strategy is the following. If

$$
\max _{a} \Pi_{I P}(a)-a-b_{0}>\max _{a, \xi} \Pi_{N I P}(a, \xi)-a
$$

pay $b_{0}$, choose a to maximize $\Pi_{I P}(a)-a$ and follow strategy IP; otherwise do not pay $b_{0}$, choose $a, \xi$ to maximize $\Pi_{N I P}(a, \xi)-a$ and follow strategy NIP.

We already mentioned that the level of capital at which accumulation stops (until the Poisson event hits) in the NIP case satisfies $M_{\alpha}<\xi_{\alpha}<$ $M$. This is a source of inefficiency, relative to the IP strategy. ${ }^{10}$ The first order condition for the optimal choice of $\xi_{\alpha}$ is

$$
\frac{\gamma}{\lambda+r}\left(\pi^{\prime}\left(\xi_{\alpha}\right)-R_{\alpha}^{\prime}\left(\xi_{\alpha}\right)\right)=\frac{\pi\left(\xi_{\alpha}\right)-R_{\alpha}\left(\xi_{\alpha}\right)}{\xi_{\alpha}}
$$

We show in Lemma A.5 that if the elasticity of $\pi(\xi)-R_{\alpha}(\xi)$ is nondecreasing then when $\gamma \rightarrow \infty, \xi_{\alpha} \rightarrow M$. Before comparing expenditure in private rent-seeking under the NIP $\left(a_{\text {nip }}\right)$ and the IP $\left(a_{i p}\right)$ strategy, we characterize better the conditions under which the IP strategy is optimal.

\subsection{Opting for Public Rent-Seeking. When $b_{0}=0$, the IP strategy}

is always adopted. Alternatively, $b_{0}$ can always be set high enough to

\footnotetext{
${ }^{10}$ When $\lambda$ is an increasing function of capacity or cumulated output, this inefficiency is stronger.
} 
make the NIP strategy more advantageous. Start then with the case in which IP is optimal in expected value, and $b_{0}$ has been paid at $t=0$. What can be said about spending $b_{1}$ ?

If the Poisson event takes place when the stock of capital is already at $M$, the innovator pays $b_{1}$ if $\pi(M) \geq R_{\alpha}(M)+b_{1}$. Because $\pi(M)-$ $R_{\alpha}(M)=(1-\alpha)^{r / \gamma}\left[\pi(M)-R_{0}(M)\right]$, it follows that, in this case, the legal monopoly is enforced whenever

$$
b_{1} \leq(1-\alpha)^{r / \gamma}\left[\pi(M)-R_{0}(M)\right]
$$

Consider next the case in which the stock of capital $k<M$ at the time the Poisson event occurs. Enforcing the legal monopoly requires paying $b_{1}$, accumulating capacity until $M$ is reached $s=(1 / \gamma) \log (M / k)$ periods later, and remaining there forever. The gain from doing this is $R_{1}(k)-R_{\alpha}(k)$, which is increasing in $k$, and has a maximum at $k=M$. Assume that $b_{1} \leq \pi(M)-R_{\alpha}(M)$ holds. At $k<M$ the continuation condition for the IP strategy becomes

$$
\left(\frac{(1-\alpha) k}{M}\right)^{r / \gamma}\left(\pi(M)-R_{\alpha}(M)\right) \geq b_{1}
$$

This holds for all

$$
k \geq \kappa=M\left[\frac{b_{1}}{(1-\alpha)^{r / \gamma}\left(\pi(M)-R_{\alpha}(M)\right)}\right]^{\gamma / r}
$$


The IP strategy can therefore be characterized in terms of a threshold stock at the time the Poisson event takes place: if $k \geq \kappa$ pay $b_{1}$; otherwise, do not. It would be nice if a similar threshold existed for the initial decision to purchase the public rent-seeking option at a price $b_{0}$; in other words if the initial choice between the IP and the NIP strategy could be reduced to having a stock $k_{0}$ larger or smaller than a certain threshold $\kappa_{0}$. Unfortunately, this is not the case as the specific functional form for $\lambda(a)$ and all other parameters of the model play a role in this decision. To see this, notice that the expected gain from paying $b_{0}$ is equal to

$$
\Pi_{I P}\left(a_{i p}\right)-\Pi_{N I P}\left(a_{n i p}, \xi_{\alpha}\right)+\left(a_{n i p}-a_{i p}\right) .
$$

The latter can be broken down into two pieces. The option value

$$
O\left(a_{i p}\right)=\int_{0}^{\infty} \lambda\left(a_{i p}\right) e^{-t \lambda\left(a_{i p}\right)} \max \left\{e^{-r t} \mu\left(k_{0} e^{\gamma t}\right), 0\right\} d t
$$

and the difference between

$$
\left(k_{0} / M\right)^{\left(\lambda\left(a_{i p}\right)+r\right) / \gamma} \frac{r}{\lambda\left(a_{i p}\right)+r}\left[\pi(M)-R_{\alpha}(M)\right]-a_{i p}
$$

and

$$
\left(k_{0} / \xi_{\alpha}\right)^{\left(\lambda\left(a_{n i p}\right)+r\right) / \gamma} \frac{r}{\lambda\left(a_{n i p}\right)+r}\left[\pi\left(\xi_{\alpha}\right)-R_{\alpha}\left(\xi_{\alpha}\right)\right]-a_{n i p}
$$


But this procedure is not as illuminating as in the previous case. This is because $a_{i p}$ is different from $a_{\text {nip }}$ and, as we show next, the two cannot be unambiguously ranked.

\section{Evaluating Private Rent-Seeking}

We move next to the issue that, from a social welfare point of view, is at the core of our model: Which one of the two strategies, the IP or the NIP, leads to a smaller expenditure in private secrecy? As long as the private, $a$, and the social, $w_{a}$, costs of private rent-seeking are positively correlated, minimizing the former should minimize the latter. Appendix B reports first and second order conditions for the choice of $a_{i p}$ and $a_{\text {nip }}$; we show there that, in general, the optimal choice of either cannot be characterized by first order conditions only, as the relevant functions are not concave with respect to $a$. We must, therefore, resort to more indirect methods to extract additional information about the relative magnitudes of $a_{i p}$ and $a_{n i p}$.

We can try estimating a bound on the equilibrium choice of $a_{\text {nip }}$ by looking at the private gains from keeping secrecy. The expected private gain is the difference between the (maximized) value of $\Pi_{N I P}$ and what the innovator would receive at time zero without any secrecy, which is $R_{\alpha}\left(k_{0}\right)$. Recall that $\xi_{\alpha}$ is the value at which $\Pi_{N I P}$ is maximized. The 
gain from secrecy is

$$
\left(\frac{k_{0}}{\xi_{\alpha}}\right)^{(\lambda+r) / \gamma} \frac{r}{r+\lambda}\left[\pi\left(\xi_{\alpha}\right)-R_{\alpha}\left(\xi_{\alpha}\right)\right]
$$

When $\lambda=\infty$ benefit is at a minimum, zero in fact (recall that $k_{0} \leq \xi_{\alpha}$ ). When $\lambda=0$ or $\gamma=\infty$, benefit is at a maximum. In fact, for $\lambda=0$ or $\gamma=\infty$ the optimal choice for $\xi_{\alpha}$ is $M$. Let us concentrate on $\lambda$ as the latter can be affected by proper choice of $a$. The maximum benefit from secrecy is $\left(k_{0} / M\right)^{r / \gamma}\left(\pi(M)-R_{\alpha}(M)\right)$, which is an upper bound on $a$. Notice that this is increasing in $k_{0}$, so expenditure in private rentseeking should be expected to be larger when the initial productive capacity is relatively high. Let $\hat{a}=\left(k_{0} / M\right)^{r / \gamma}\left(\pi(M)-R_{\alpha}(M)\right)$, and $\iota=\lambda(\hat{a})$. Then, the optimal choice of $a$ must result in $\lambda \geq \iota$. This in turn gives the following bound

$$
a_{n i p} \leq\left(\frac{k_{0}}{\xi_{\alpha}}\right)^{(\iota+r) / \gamma} \frac{r}{r+\iota}\left(\pi\left(\xi_{\alpha}\right)-R\left(\xi_{\alpha}\right)\right) .
$$

A similar argument applies to $a_{i p}$. The maximum gain from secrecy in this case is equal to

$$
a_{i p} \leq\left(\frac{k_{0}}{M}\right)^{(\iota+r) / \gamma} \frac{r}{r+\iota}(\pi(M)-R(M))+\Delta O
$$

where $\Delta O$ denotes the variation in the option value $O$ attributable to a decrease in $\lambda$. Notice that, in general, the two bounds are not rankable; nevertheless, at least for values of $\gamma$ that are high in relation to $\iota+r$, 
one would expect the upper bound for $a_{i p}$ to be larger than that for $a_{n i p}$, even when $\Delta O$ is zero.

As discussed in the introduction, one major rationale for allowing public rent-seeking is that the latter may lead to substantial lower levels of private rent-seeking, thereby sparing society that source of inefficiency. This argument would be a rather convincing one in favor of the establishment of legal monopolies if one could show that, in general, the level of expenditure in private rent-seeking that obtains when the IP strategy is optimal, $a_{i p}$, is much lower than the one chosen when the NIP strategy is followed, $a_{n i p}$. Unfortunately it is not obvious that, in the general case, $a_{i p}<a_{n i p}$. We have already seen, in fact, that the maximum gains from private rent-seeking may well be higher when the IP strategy is chosen than when it is not. Essentially the same argument implies that, in certain important cases, $a_{i p}>a_{\text {nip }}$ actually holds. To see this we proceed in steps.

Fix $k_{0}$ and $\alpha \in(0,1)$ and consider first the case in which the vector $b$ is high enough that IP is not optimal. Then the strategy NIP will be adopted and a level of expenditure equal to $a_{\text {nip }}$ will be maintained, independently of the particular value of $b$. The innovator becomes indifferent between the IP and the NIP strategy when

$$
\Pi_{N I P}\left(a_{n i p}, \xi_{\alpha}\right)-a_{n i p}=\Pi_{I P}\left(a_{i p}\right)-a_{i p}-b_{0} .
$$


We are interested in determining which, between $a_{n i p}$ and $a_{i p}$, is higher at this point. The cost of increasing $a$ is the same in both cases, so let us compare the payoffs from decreasing $\lambda$ via a rise in $a$. The derivative of $\Pi_{N I P}$ with respect to $\lambda$ is

$$
\left[\Pi_{N I P}\left(\lambda, \xi_{\alpha}\right)-R_{\alpha}\left(k_{0}\right)\right]\left[-t\left(\xi_{\alpha}\right)-\frac{1}{\lambda+r}\right]
$$

while the derivative of $\Pi_{I P}$ is

$$
\left[\Pi_{I P}(\lambda)-R_{\alpha}\left(k_{0}\right)-O(\lambda)\right]\left[-t(M)-\frac{1}{\lambda+r}\right]+O^{\prime}(\lambda)
$$

First, we compute

$$
O^{\prime}(\lambda)=-\int_{t=0}^{\infty} \lambda(a) e^{-\lambda t}(t-(1 / \lambda)) \max \left\{e^{-r t} \mu\left(k_{0} e^{\gamma t}\right), 0\right\} d t
$$

In particular, if $1 / \lambda$, the expected length of time until the secret leaks out, is smaller than the time at which $\kappa$ is reached, $t_{\kappa}=\log \left(\kappa / k_{0}\right) / \gamma$, then $O^{\prime}(\lambda)>0$.

Next, compare the rest of the two equations term by term, holding $\lambda$ constant at $\lambda\left(a_{N I P}\right)$. The term within the first square parentheses is positive, while the second is negative. Because $M>\xi_{\alpha}$, the term within the second square parentheses is always larger, in absolute value, in the IP equation. Write the term within the first square parentheses as:

$$
\left(\frac{k_{0}}{\xi_{\alpha}}\right)^{(\lambda+r) / \gamma} \frac{r}{r+\lambda}\left[\pi\left(\xi_{\alpha}\right)-R_{\alpha}\left(\xi_{\alpha}\right)\right]
$$


in the NIP case and

$$
\left(\frac{k_{0}}{M}\right)^{(\lambda+r) / \gamma} \frac{r}{r+\lambda}\left[\pi(M)-R_{\alpha}(M)\right]
$$

in the IP case. The former is always larger than the latter, since $\xi_{\alpha}$ is chosen to maximize this expression and there is no immediate result concerning $a_{i p}$ versus $a_{n i p}$. Hence, and contrary to the initial presumption, allowing for public rent-seeking does unambiguously reduce wasteful expenditure in private rent-seeking.

We now complete the analysis by giving a class of examples where $a_{i p}>a_{n i p}$, or equivalently $\lambda_{n i p}<\lambda_{i p}$. The case relatively favorable to NIP is $\gamma$ large; in this case $\xi_{\alpha}$ approaches $M$ and the NIP distortion is small. In making $\gamma$ large, we at the same time consider $k_{0}$ small, to keep the length of time to the profit peak from changing as $\gamma$ gets larger. Specifically, fix $k_{1}$. Then it takes $t=(1 / \gamma) \log \left(k_{1} / k_{0}\right)$ to move from $k_{0}$ to $k_{1}$; hence, $t$ remains constant if $k_{0}$ is appropriately decreased as $\gamma$ is increased. We are especially interested in the time $1 / \lambda_{\text {nip }}$, which is the mean length of time it takes for the secret to leak out, and in the level of capital $\kappa$ for which $\mu(\kappa)=0$. Notice that as $\gamma \rightarrow \infty$ we have $\kappa \rightarrow 0$. If it takes $1 / \lambda_{\text {nip }}$ to reach $\kappa$ then we see that $k_{0}=\kappa e^{-\gamma / \lambda_{n i p}}$, which we will adopt for purposes of constructing an example. This implies that as $\gamma \rightarrow \infty$ we also have $O^{\prime}(\lambda)<\underline{O}<0$. On the other hand, the 
difference between the first term of the profit derivatives satisfies

$$
\begin{aligned}
& \left(\frac{\kappa e^{\left.-\gamma / \lambda_{n i p}\right)}}{\xi_{\alpha}}\right)^{\left(\lambda_{n i p}+r\right) / \gamma} \frac{r}{r+\lambda_{n i p}}\left[\pi\left(\xi_{\alpha}\right)-R_{\alpha}\left(\xi_{\alpha}\right)\right]- \\
& \left(\frac{\kappa e^{-\gamma / \lambda_{n i p}}}{M}\right)^{\left(\lambda_{n i p}+r\right) / \gamma} \frac{r}{r+\lambda_{n i p}}\left[\pi(M)-R_{\alpha}(M)\right] \rightarrow 0
\end{aligned}
$$

as $\gamma \rightarrow \infty$. Consequently, there are parameter values $\gamma, \lambda_{n i p}, b_{1}, b_{0}$ such that a small decrease in $b_{0}$ causes private expenditure in secrecy to jump up from $a_{n i p}$ to $a_{i p}>a_{n i p}$.

We complete our discussion of private rent-seeking by considering the dependence of $a$ on $\alpha$. Notice that $a$ increases as $\alpha$ decreases, which makes sense. Innovators that are operating in industries in which, when the secret is lost, a large competitive fringe appears have a stronger incentive to invest in keeping the secret. Also, in the case of public rent-seeking, the threshold level $\kappa$ is lower when $\alpha$ is small. This also makes sense: when $\alpha$ is small an innovator has a stronger incentive to grab the legal monopoly if he has chosen the IP strategy to begin with.

\section{Welfare Implications}

We have built our model to understand some of the welfare consequences of different IP policies. Here we attack the problem from two points of view. First, we consider the traditional welfare or mechanism design approach in which it is assumed that a benevolent government 
sets out to maximize social welfare. We explore the consequences of this assumption for choices concerning $b$. Then we turn to the case of more practical relevance, the case in which government is either selfserving, or in which regulatory capture takes place. We then ask the question of which choices of $b$ maximize government income.

5.1. Mechanism Design Perspective. We consider primarily the choice between IP and no IP. The latter can be obtained by simply setting $b$ high, although because of the problems of rent-seeking government outlined in the next subsection, a formal commitment, such as a constitutional prohibition of patents of the sort used in Switzerland until the middle 1970s, is likely to be more useful. We also comment, when IP is the optimal policy, on the implications of the model for the choice of the two components of $b$.

There are several factors one needs to consider in comparing social welfare between IP and no IP. Allowing IP leads most obviously to the deadweight loss of consumer surplus

$$
\left(k_{0} / M\right)^{r / \gamma}[U(M)-u(M)]
$$

weighted by the probability that the IP option is used. Second, there is the social cost due to secrecy, that is, the loss $w_{a}$ due to large values of a. Third, there is the fact that without IP, the innovator will produce 
less prior to the loss of the secret, while it will produce more after it. Let us provide an estimate for this loss. Specifically, let $S_{\xi_{\alpha}}$ be the flow social loss from stopping at $\xi_{\alpha}$ rather than growing to $M$ as quickly as possible. The social loss from stopping at $\xi_{\alpha}$ when there is no IP is

$$
w_{\xi}=\left(\frac{k_{0}}{\xi_{\alpha}}\right)^{(\lambda+r) / \gamma} \frac{r}{r+\lambda} S_{\xi_{\alpha}}
$$

Finally, there is the loss $w_{b}$ from public rent-seeking. In the traditional approach this latter cost, including the cost of enforcement, is ordinarily ignored, and we will do so here, even if this cost may be large in practice.

The clearest case is the case discussed above in which $\gamma$ is large and $k_{0}$ small. We showed in this case the IP leads to more secrecy than no IP. In addition, we showed in this case that $\xi_{\alpha}$ is close to $M$ so that $S_{M_{\alpha}}$ is negligible. If $\kappa<k_{0}$ so that the IP option is always used, the deadweight loss of consumer surplus remains significant when there is IP. In this case we can conclude that no IP is better than IP. A similar conclusion is reached when $\lambda$ is very large, so the secret leaks away more or less immediately. Specifically, recall that $\hat{a}=\left(k_{0} / M\right)^{r / \gamma}(\pi(M)-$ $\left.R_{\alpha}(M)\right)$, and that $\iota=\lambda(\hat{a})$, and suppose that $\iota \rightarrow \infty$. Here we cannot conclude that there is less secrecy without IP, but from our bound on 
$a$ we get

$$
a_{\text {nip }} \leq\left(\frac{k_{0}}{\xi_{\alpha}}\right)^{(\iota+r) / \gamma} \frac{r}{r+\iota}\left(\pi\left(\xi_{\alpha}\right)-R\left(\xi_{\alpha}\right)\right) \text {. }
$$

In this case there is not very much secrecy at all as the right hand side goes to zero with $\iota \rightarrow \infty$, so the cost of private rent-seeking is negligible. As in the case of large $\gamma$, we conclude that $w_{\xi_{\alpha}}$ is small, yet making $\lambda$ larger does not reduce the probability-weighted deadweight loss.

The case where $\kappa>k_{0}$ is less clear-cut. In this case the deadweight loss of consumer surplus will generally fall to zero as well, so the comparison is now ambiguous. This, incidentally, provides a strong rationale against setting $b_{1}=0$. When $b_{1}=0$ necessarily $\kappa<k_{0}$. Notice in passing that the threshold level $\kappa$ is smaller when $\alpha$ is smaller. This means higher social costs under IP: goods for which $\alpha$ is near zero are goods with the potential of being easily copied and reproduced. Consequently, the social cost of not reaching a high consumption level is quite large. In this case public rent-seeking has a higher social cost than otherwise.

Intellectual property is likely to be more useful when $\lambda$ is small. There are two caveats to this. When $\lambda$ is small to start with, a low level of $a$, with a correspondingly low level of $w_{a}$, may be enough to lead it to be zero, in which case the gain from allowing public rent-seeking 
disappears if $w_{b}>0$. Further, the lower is $\lambda$ the higher is the consumer loss from allowing for public monopoly, which further reduces the social gains from setting $b_{0}=0$.

The role of the parameter $\alpha$ in affecting the optimality of IP is also fairly straightforward to outline. At the two opposite extremes, $\alpha=0$ and $\alpha=1$, allowing for access to public rent-seeking does not appear socially useful. In the first case, even if private rent-seeking may be high when losing the secret implies losing monopoly profits almost immediately, the consumer loss from maintaining monopoly forever via the IP option is particularly high. In the second case, monopoly power is already high to start with and maintained for a long time even after the secret leaks. In this case one would expect low levels of $a$ and, correspondingly, low levels of $w_{a}$, with small gains from introducing public IP. Further, at high values of $\alpha$, the target stock $\xi_{\alpha}$ is likely to be closer to $M$, the target value under IP, and this also reduces the social gains from allowing for public IP.

We have shown that $\pi(M) \geq R_{\alpha}(M)+b_{1}$ must hold for people to use IP. Hence, should it be optimal to have people use IP instead of NIP, this inequality shows that the size of $b$ should be chosen to depend on $\alpha$. What this implies is that a uniform patent policy across different sectors is not desirable. The optimal patent policy varies 
from sector to sector, depending on $\alpha, \gamma$, and $\lambda$. If one moves away from the assumption of a benevolent and fully informed planner, this observation underlies the intrinsic difficulty of designing an optimal IP policy. An effective patent policy requires a considerable amount of private information to be made available to the regulator, and the latter to engage in an equally considerable amount of fine-tuning of patent law, from sector to sector, and from market to market.

In summary, our analysis suggests that the most favorable case for IP is when $\lambda$ is not particularly high and decreases slowly, $\gamma$ is low and $\alpha$ is an intermediate value. Moreover, there is substantial benefit from using $b_{1}$ as a policy instrument rather than $b_{0}$. By using $b_{1}$ we can get $\kappa>k_{0}$ so that the option will not always be used, and this mitigates the consumer deadweight loss. Indeed, taking into account the consumer loss from low output and slow growth in productive capacity, we would want to choose $b_{1}$ large enough that no grabbing of the IP option occurs before $\xi_{\alpha}$ is reached, as the latter would be reached in any case even when IP is not allowed. A fortiori, then, one is led to conclude that the optimal level of $b_{1}$ is such that $\kappa=M$ holds, if this is feasible given the other parameter values.

5.2. Endogenous Patent Cost. What if $b$ is determined endogenously? With this we mean that there is no benevolent planner trying 
to design the socially optimal mechanism, but instead a profit maximizer setting the vector $b$ in order to maximize his own benefits.

The main case to consider is, obviously, the one in which the planner is maximizing personal pecuniary benefits from setting $b$. That is, the case in which the government is composed of self-seeking individuals acting in their own private interest. In this case it is straightforward to notice that the planner will set $b$ at a level high enough to make the innovator almost indifferent, in expected terms, between the IP and the NIP strategy. Notice that, as we have shown above, the value of the dynamic component of the IP option $O(t)$ increases with time. In fact, for a given level of $b_{1}$, that option has zero value until a certain threshold is crossed, and it keeps increasing until a productive capacity equal to $M$ is reached. This behavior of the public sector, though, leads us to the case considered at the end of the previous section in which $\Pi_{N I P}\left(a_{n i p}, \xi_{\alpha}\right)-a_{n i p}=\Pi_{I P}\left(a_{i p}\right)-b_{0}-a_{i p}$ and $O^{\prime}\left(a_{i p}\right) \geq 0$. Then we have that, unambiguously, $a_{i p}>a_{n i p}$, so that $w_{a_{i p}}>w_{a_{n i p}}$, and the availability of public rent-seeking makes everybody worse off (with the exception of the government).

The intuition behind this result is clear: when the government sets fees for legal enforcement of monopoly high enough to make the innovator nearly indifferent between using and not using the $b$ option, then 
an innovator that is following the IP strategy has a stronger incentive to postpone the Poisson event than an innovator that is following the NIP strategy. This is because of two reasons. First, the innovator following the IP option is earning higher profits from being at or near $M$ instead of $\xi_{\alpha}$, even if this may be compensated by the fact that he gets to $M$ somewhat later and with lower probability. Second, the innovator is trying to accumulate enough capital so that the threshold level $\kappa$ is crossed and the IP option $O(t)$ takes on a positive value. We claim this situation is more relevant than one would like to think, as the frequent cases of regulator capture, intense lobbying to allow for extensions of IP protection, long and costly litigations between government agencies and monopolies (ending with monopolies buying their way out of court, as in the Microsoft case) all seem to confirm.

With optional patenting, as in this model, the innovator gets at least the same return as without the patent system. But in practice the patent may be awarded to someone else. Ponce [2003] points to some subtle issues that arise under the "existing practice" component of patent law. Less subtle issues arise when the application of the law is endogenous: unless the government can commit to giving the patent to the right party, there is a holdup problem. A patent now acts like a business license - a firm cannot do business without the patent, since 
if it does not get it someone else will. In extreme cases all rent is extracted, the innovator earns nothing, and there is no innovation. However, it may be that it is impossible to charge for the license until after the secret leaks out. In this case monopoly profits can be either smaller or bigger than competitive rent. So there may be less innovation with IP than without it for this reason alone. Another possibility is that the government does not have the capability of allocating narrow and well specified patents to "true innovators" - it may, instead, randomly allocate the rights by issuing vague patents to general ideas; in this case the patent holders can charge the innovator(s) that makes use of the general idea to which they claim a patent. This poses a big problem due to commitment, since the government might be able to commit not to hold up the innovator - but a bunch of scattered individuals clearly cannot credibly do the same, nor will they. In practice we see a lot of this: submarine patents, patenting things other people have done, and so forth.

In the absence of commitment, it is interesting to consider in more detail the case in which the planner sets $b_{1}$ after the secret is revealed in order to maximize his own profit at that stage. In this case the lack of commitment on the part of the planner may reduce his profits 
from the sale of patents and lead to less private rent-seeking than otherwise. ${ }^{11}$ Notice that one of the reasons for which an innovator may want to spend a larger amount on $a$ when the IP strategy is chosen than when it is not is to earn the opportunity of making $O(t)>0$, because the latter increases in value when capacity is accumulated. If, on the other hand, the planner is unable to commit to a certain level for $b_{1}$, what the innovator should expect is the planner increasing it as long as the secret is not revealed. If this is the case, then $O(t)=0$ for all $t$ and $O^{\prime}(a)=0$ as well. Hence, this crucial incentive to raise $a_{i p}$ above $a_{\text {nip }}$ dissolves. In this case, even if $\gamma$ is particularly large, the private return from increasing $a$ is higher along the NIP than the IP strategy. These circumstances may actually lead to the least damaging social arrangement, assuming the innovation rate is not affected by the planner's inability to commit. To see this notice that, in order to maximize earnings from $b_{1}$, the planner would set $b_{0}=0$, thereby luring innovators into chasing the IP strategy. In these particular circumstances the latter, as we have just argued, implies lower private

\footnotetext{
${ }^{11}$ Obviously, a complete analysis would also show that lack of commitment also leads to much less innovation altogether, thereby making society much worse off. Hence, the argument that follows should be taken cum granum salis.
} 
rent-seeking than the NIP one, thereby reducing the social cost from secrecy.

Some final observations are potentially interesting. When the innovator has private information about how valuable and costly the innovation is, circumstances will generally make things worse (from a social perspective) for allowing public protection of IP, since the optimal price to charge will necessarily have some people self-selecting not to innovate. The political economy of patents has perhaps to some extent escaped the attention of those large multi-national (read U.S.) corporations lobbying most intensively in favor of international patent protection through the WTO. The fact is that local tribunals are most likely to award monopolies to locals. As for international tribunals, perhaps it is wise to keep in mind the ice-skating judges at the Olympic games.

\section{Conclusion}

We have built a model of innovation in which legal protection of intellectual property may play a socially valuable role. This potentially useful role follows from two assumptions: (i) that the sole innovator has access to a costly private technology to keep secrecy and avoid competition from imitators, (ii) that monopoly rights may also be purchased 
via the public legal system. One would hope that the availability of the public option leads to a smaller social cost of keeping the monopoly power by inducing the innovator to waste less resources in the private secrecy-keeping (and rent-seeking) technology. By allowing for a tradeoff between public and private rent-seeking, we therefore entertain the possibility that the existence of patents and similar legal devices may find a welfare justification in the reduction of wasteful private rentseeking they bring about. The final result is rather mixed. Even in this, purposefully favorable, setting, the case for patents and legal IP protection turns out to endure analytical scrutiny poorly.

We show, in fact, that even when a benevolent central planner exists who is able to fully commit to the socially optimal policy, legal IP protection is desirable only under special parametric circumstances. While it is far from obvious that such circumstances, as detailed in the previous section, are empirically relevant, it should be kept in mind that, according to the analysis carried out here, the optimal patent policy is one that treats different goods, different industries, and different markets differently. Therefore, even leaving aside the realism of the parametric assumptions under which patents are a socially useful tool, one remains with the need of justifying the possession, on the part of the supposedly benevolent planner, of the detailed information 
necessary to fine tune the cost of patents to the specific requirements of each case. Mentioning the human fallibility of benevolent planners brings to mind another of their most interesting properties: lack of existence. Which leads to what we consider the main, or at least the most surprising, result of this paper.

We show that, when the cost of public IP protection is high, then the innovator spends more when the IP option is available than when it is not. Next, we show that selfish governments pursuing their self-interest will push the cost of providing public IP protection exactly toward that level. In conclusion, our analysis shows that the availability of patents leads to a lose-lose proposition: when IP is set and managed by a selfinterested government, private expenditure in secrecy is at its highest, and the deadweight loss for consumers due to monopoly power is also maximized.

There are many objections that can be raised to our analysis for example, capital market imperfections may lead to some unpriced spillovers. But these types of frictions are not unique to investment in ideas and creations - and while investment of all types may be reduced by capital market imperfections, it is not ordinarily suggested that the solution is a government grant of monopoly power. Our results here point to the ambiguity of theoretical analysis of intellectual property. 
It is clear, as we argue in this context, that allowing the government to grant monopolies is extremely dangerous - and we should require clear and compelling evidence before doing so. Since theoretical argument is insufficient to settle the point, since empirical evidence is almost non-existent, and since anecdotal evidence strongly suggests that intellectual property reduces rather than encourages innovation, there should be a strong presumption against patents and copyrights. It is our view that they should be abolished pending strong and persuasive evidence that they actually do some good. 


\section{Appendix A. Proofs}

Recall that $t(k)$ is the time it takes to reach $k$ from $k_{0}$ when the capital stock grows at the rate $\gamma$. A useful consequence of this definition, often used in our calculations, is that $e^{-r(t(\kappa)-t(\xi))}=(\xi / \kappa)^{r / \gamma}$.

\section{A.1. The function $R_{\alpha}(k)$.}

Lemma A.1. The maximum net present value of profits starting with a productive capacity $k$ when the Poisson event strikes and the IP option is not taken is

$R_{\alpha}(k)=r \int_{0}^{s} e^{-r t} \pi\left(k e^{\gamma t}\right) d t+\left(\frac{k}{M}\right)^{r / \gamma}\left[\pi(M)-(1-\alpha)^{r / \gamma}\left(\pi(M)-R_{0}(M)\right)\right]$.

Further, $R_{\alpha}(M) \leq \pi(M)$, and as $\gamma \rightarrow \infty, R_{\alpha}(k) \rightarrow R_{0}(k)$. The time spent at $M$ is $s^{\prime}=(1 / \gamma) \log (1 /(1-\alpha))$.

Proof. Since it cannot be optimal to allow the capital stock to exceed $M$ before the Poisson event, we may assume $k \leq M$, where recall that $M$ is the level of productive capacity at which $\pi(c)$ is maximized. After the Poisson event, the capacity controlled by the competitive fringe is $(1-\alpha) k$, always growing at $\gamma$. Innovator's capacity is $\alpha k$. We argued in the text that the optimal plan for the innovator is to allow his own capital to grow until industry capacity reaches $M$, then decrease his own capital to keep industry capacity at $M$ until he runs out of capital. 
Starting at $k$, it takes $s=(1 / \gamma) \log (M / k)$ units of time for industry capacity to reach $M$.

To calculate the length of the interim period during which the industry remains at $M$, observe that $s^{\prime}$ units of time after reaching $M$ the competitive fringe has increased its capital stock by

$$
(1-\alpha) M\left(e^{\gamma s^{\prime}}-1\right)
$$

When this is equal to $\alpha M$ the innovator runs out of capital; this occurs when $s^{\prime}=(1 / \gamma) \log (1 /(1-\alpha))$.

We are now in position to compute the value for the innovator of a stock of capital $k$ when the event strikes, and a share $(1-\alpha)$ of productive capacity goes to competitors. This is

$R_{\alpha}(k)=r \int_{0}^{s} e^{-r t} \pi\left(k e^{\gamma t}\right) d t+r \int_{s}^{s+s^{\prime}} e^{-r t} \pi(M) d t+r \int_{s+s^{\prime}}^{\infty} e^{-r t} \pi\left(M e^{\gamma t}\right) d t$.

Since $M$ maximizes $\pi$, which is single-peaked, it follows directly that $R_{\alpha}(M) \leq \pi(M)$. Simplification yields the expression given in the conclusion, and the limit as $\gamma \rightarrow \infty$ follows directly from this expression.

We now show

Lemma A.2. $R_{\alpha}$ is single peaked. The (unique) maximizer $M_{\alpha}$ satisfies $R_{\alpha}\left(M_{\alpha}\right)=\pi\left(M_{\alpha}\right)$, is increasing in $\alpha$ and $M_{1}=M$. 
Proof. Recall that $R_{0}(k)=r \int_{0}^{\infty} e^{-r t} \pi\left(k e^{\gamma t}\right) d t$. We may introduce the change of variable $\kappa=k e^{\gamma t}$ so that $\gamma t=\log (\kappa / k), d \kappa=\gamma k e^{\gamma t} d t=$ $\gamma \kappa d t, e^{-r t}=(\kappa / k)^{-r / \gamma}$ and

$$
R_{0}(k)=(r / \gamma) k^{r / \gamma} \int_{k}^{\infty}(1 / \kappa)^{r / \gamma+1} \pi(\kappa) d \kappa
$$

Taking the first derivative of $R_{0}(k)$ with respect to $k$ we find

$$
R_{0}^{\prime}(k)=(r / \gamma k)\left[R_{0}(k)-\pi(k)\right]
$$

Since by Lemma A.1 $R_{0}(M) \leq \pi(M)$ and $\pi$ is single-peaked, $R_{0}$ is also single-peaked.

Now write

$$
\begin{aligned}
R_{\alpha}(k) & =r \int_{0}^{s} e^{-r t} \pi\left(k e^{\gamma t}\right) d t+\left(\frac{k}{M}\right)^{r / \gamma}\left[\pi(M)-(1-\alpha)^{r / \gamma}\left(\pi(M)-R_{0}(M)\right)\right] \\
& =R_{0}(k)+\left(\frac{k}{M}\right)^{r / \gamma}\left[\left(1-(1-\alpha)^{r / \gamma}\right)\left(\pi(M)-R_{0}(M)\right)\right] .
\end{aligned}
$$

Computing the derivative, and substituting in $R_{0}^{\prime}(k)$ we have

$$
\begin{aligned}
R_{\alpha}^{\prime}(k) & =R_{0}^{\prime}(k)+(r / \gamma k)\left[R_{\alpha}(k)-R_{0}(k)\right] \\
& =(r / \gamma k)\left[R_{\alpha}(k)-\pi(k)\right] .
\end{aligned}
$$

Since $R_{\alpha}(M) \leq \pi(M)$ and $\pi$ is single-peaked, $R_{\alpha}$ is also single-peaked. Moreover, it is clear that the unique maximizer $M_{\alpha}$ satisfies $R_{\alpha}\left(M_{\alpha}\right)=$ $\pi\left(M_{\alpha}\right)$. Since increasing $\alpha$ strictly increases $R_{\alpha}$ it strictly increases 
$R_{\alpha}^{\prime}(k)$ and since $R_{\alpha}$ is single peaked, it follows that $M_{\alpha}$ is strictly increasing.

Finally, substituting into $R_{\alpha}(k)$, we find $R_{1}(M)=\pi(M)$. This implies that $M_{1}=M$.

A.2. Value of Optimal Strategies. In doing computations that involve plans of growing as quickly as possible to a particular target capacity level $\xi$ and then staying there, it is convenient to define the corresponding time path of the capacity as

$$
k(t, \xi)=\min \left\{k_{0} e^{\gamma t}, \xi\right\}
$$

It is useful also to define the profit from sticking to this time path of capacity for a length of period equal to $\tau$ as

$$
\Pi_{\xi}(\tau)=r \int_{0}^{\tau} e^{-r t} \pi(k(t, \xi)) d t
$$

where, of course, $\Pi_{M}(\infty)=R_{1}\left(k_{0}\right)$.

Lemma A.3. The average present value profit when the IP option is not used, the expenditure in private rent-seeking is a and the pre-event stopping target is $\xi$ is

$$
\Pi_{N I P}(a, \xi)=R_{\alpha}\left(k_{0}\right)+\left(k_{0} / \xi\right)^{(\lambda+r) / \gamma} \frac{r}{\lambda+r}\left(\pi(\xi)-R_{\alpha}(\xi)\right) .
$$


Proof. Our first step is to derive the expressions used in the main text to define $\Pi_{N I P}(a, \xi)$ and $\Pi_{I P}(a)$. First we consider $\Pi_{N I P}(a, \xi)$. By definition

$$
\Pi_{N I P}(a, \xi)=\int_{0}^{\infty} \lambda e^{-\lambda t}\left(\Pi_{\xi}(t)+e^{-r t} R_{\alpha}(k(t, \xi))\right) d t .
$$

To compute $\Pi_{N I P}(a, \xi)$, set $\tau=t(\xi)=(1 / \gamma) \log \left(\xi / k_{0}\right)$. Recall that

$$
R_{\alpha}(k)=r \int_{0}^{s} e^{-r t} \pi\left(k e^{\gamma t}\right) d t+\left(\frac{k}{M}\right)^{r / \gamma}\left[\pi(M)-(1-\alpha)^{r / \gamma}\left(\pi(M)-R_{0}(M)\right)\right] .
$$

Consider first $t<\tau$. Then

$$
\Pi_{\xi}(t)+e^{-r t} R_{\alpha}(k(t, \xi))=R_{\alpha}\left(k_{0}\right)
$$

Consider next $t \geq \tau$

$$
\begin{gathered}
\Pi_{\xi}(t)+e^{-r t} R_{\alpha}(k(t, \xi))= \\
\Pi_{\xi}(\tau)+e^{-r \tau}\left(1-e^{-r(t-\tau)}\right) \pi(\xi)+e^{-r t} R_{\alpha}(\xi)= \\
R_{\alpha}\left(k_{0}\right)+e^{-r \tau}\left(1-e^{-r(t-\tau)}\right) \pi(\xi)+e^{-r t} R_{\alpha}(\xi)-e^{-r \tau} R_{\alpha}(\xi)= \\
R_{\alpha}\left(k_{0}\right)+e^{-r \tau}\left(1-e^{-r(t-\tau)}\right)\left(\pi(\xi)-R_{\alpha}(\xi)\right) .
\end{gathered}
$$

Hence, integrating over $t<\tau$ and $t \geq \tau$ we find

$$
\begin{gathered}
\Pi_{N I P}(a, \xi)=\int_{\tau}^{\infty} \lambda e^{-\lambda t}\left(\Pi_{x}(t)+e^{-r t} R_{\alpha}(k(t, \xi))\right) d t= \\
R_{\alpha}\left(k_{0}\right)+\int_{\tau}^{\infty} \lambda e^{-\lambda t} e^{-r \tau}\left(1-e^{-r(t-\tau)}\right)\left(\pi(\xi)-R_{\alpha}(\xi)\right) d t= \\
R_{\alpha}\left(k_{0}\right)+e^{-(\lambda+r) \tau} \int_{0}^{\infty} \lambda e^{-\lambda t}\left(1-e^{-r t}\right)\left(\pi(\xi)-R_{\alpha}(\xi)\right) d t=
\end{gathered}
$$




$$
\begin{gathered}
R_{\alpha}\left(k_{0}\right)+e^{-(\lambda+r) \tau}\left(1-\frac{\lambda}{\lambda+r}\right)\left(\pi(\xi)-R_{\alpha}(\xi)\right)= \\
R_{\alpha}\left(k_{0}\right)+e^{-(\lambda+r) \tau} \frac{r}{\lambda+r}\left(\pi(\xi)-R_{\alpha}(\xi)\right) \\
\times R_{\alpha}\left(k_{0}\right)+\left(k_{0} / \xi\right)^{(\lambda+r) / \gamma} \frac{r}{\lambda+r}\left(\pi(\xi)-R_{\alpha}(\xi)\right)
\end{gathered}
$$

Lemma A.4. The average present value profit (net of b) when the IP option is used, and the expenditure in private rent-seeking is a is

$$
\begin{aligned}
\Pi_{I P}(a) & =R_{\alpha}\left(k_{0}\right)+\left(k_{0} / M\right)^{(\lambda(a)+r) / \gamma} \frac{r}{\lambda(a)+r}\left[\pi(M)-R_{\alpha}(M)\right] \\
& +\int_{0}^{\infty} \lambda(a) e^{-(\lambda(a)+r) t} \max \left\{\mu\left(k_{0} e^{\gamma t}\right), 0\right\} d t
\end{aligned}
$$

Proof. Recall that in the text we defined the gain over $R_{\alpha}(k)$ from the plan that involves paying $b_{1}$ as

$$
\mu(k)=\left\{\begin{array}{cc}
R_{1}(k)-R_{\alpha}(k)-b_{1} & k<M \\
\pi(M)-R_{\alpha}(M)-b_{1} & k \geq M
\end{array} .\right.
$$

If follows directly that

$$
\begin{aligned}
\Pi_{I P}(a) & =\int_{0}^{\infty} \lambda e^{-\lambda t}\left(\Pi_{M}(t)+e^{-r t}\left(R_{\alpha}(k(t, M))+\max \{\mu(k(t, M)), 0\}\right)\right) d t \\
& =\Pi_{N I P}(a, M)+\int_{0}^{\infty} \lambda e^{-\lambda t} \max \{\mu(k(t, M)), 0\} d t
\end{aligned}
$$

and the expression for $\Pi_{I P}(a)$ follows directly from Lemma A.3. 
A.3. Choice of $\xi_{\alpha}$. Finally, we characterize $\xi_{\alpha}$ for the NIP and the IP strategy, respectively. Define $m(\xi)=\pi(\xi)-R_{\alpha}(\xi)$.

Lemma A.5. The optimal stopping rule $\xi_{\alpha}$ satisfies

$$
\frac{m^{\prime}\left(\xi_{\alpha}\right) \xi_{\alpha}}{m\left(\xi_{\alpha}\right)}=\left(\frac{\lambda+r}{\gamma}\right)
$$

Suppose in addition that the elasticity of $m(\xi)$ is non-decreasing. Then the solution of the first order condition is unique. This solution $\xi_{\alpha}$ is increasing in $\gamma$, decreasing in $\lambda$, and $r$; it satisfies $M>\xi_{\alpha}>M_{\alpha}$. Moreover, as $\gamma \rightarrow \infty, \xi_{\alpha} \rightarrow M$.

Proof. To compute $\xi_{\alpha}$ from Lemma A.3 we differentiate

$$
\Pi_{N I P}(a, \xi)=R_{\alpha}\left(k_{0}\right)+\left(k_{0} / \xi\right)^{(\lambda+r) / \gamma} \frac{r}{\lambda+r}\left(\pi(\xi)-R_{\alpha}(\xi)\right)
$$

with respect to $\xi$, getting the first order condition

$$
\xi_{a}\left(\pi^{\prime}\left(\xi_{a}\right)-R_{\alpha}^{\prime}\left(\xi_{a}\right)\right)=\left(\frac{\lambda+r}{\gamma}\right)\left(\pi\left(\xi_{a}\right)-R_{\alpha}\left(\xi_{a}\right)\right)
$$

which we may write using $m$ as

$$
\frac{m^{\prime}\left(\xi_{\alpha}\right) \xi_{\alpha}}{m\left(\xi_{\alpha}\right)}=\left(\frac{\lambda+r}{\gamma}\right)
$$

When the elasticity of $m(\xi)$ is non-decreasing, it is apparent that this equation has a unique solution. We already observed that it cannot be optimal to allow the capital stock to exceed $M$ before the Poisson event, 
that is, $\xi_{\alpha}<M$. By Lemma A.2 $R_{\alpha}\left(M_{\alpha}\right)=\pi\left(M_{\alpha}\right)$. This, together with the fact that $\pi^{\prime}\left(M_{\alpha}\right)>0$ and $R_{\alpha}^{\prime}\left(M_{\alpha}\right)=0$, implies $\xi_{\alpha}>M_{\alpha}$.

Finally, we notice that $\xi_{\alpha}$ is increasing in $\gamma$ and decreasing in $\lambda$ and $r$, as intuition would suggest. The behavior of $\xi_{\alpha}$ at large values of $\gamma$ is particularly relevant for our analysis. From Lemma A.2 when $\gamma \rightarrow \infty, R_{\alpha}(k) \rightarrow R_{0}(k)$. This and the first order condition given above imply that when $\gamma \rightarrow \infty, \xi\left(\pi^{\prime}(\xi)-R_{0}^{\prime}(\xi)\right)=0$ must hold. But $R_{0}^{\prime}(k)=(r / \gamma k)\left[R_{0}(k)-\pi(k)\right]$ implies that $R_{0}^{\prime}(k)=0$ for all $k$ when $\gamma \rightarrow \infty$. Hence, the first order condition boils down to $\xi_{\alpha} \pi^{\prime}\left(\xi_{\alpha}\right)=0$, which implies $\xi_{\alpha} \rightarrow M$ for $\gamma \rightarrow \infty$.

\section{Appendix B. Optimal Secrecy}

Here we discuss the optimal choices of $a_{\text {nip }}$ and $a_{i p}$. Inspection of the functions $\Pi_{N I P}(a, \xi)$ and $\Pi_{I P}(a)$ shows they are not concave with respect to $a$, hence both first and second order conditions need to be checked, and the global maximum cannot be characterized directly.

We start with $a_{\text {nip }}$, by differentiating $\Pi_{N I P}(a, \xi)-a$ with respect to a. This yields

$$
\frac{\lambda^{\prime}(a) r\left(\pi(\xi)-R_{\alpha}(\xi)\right)}{\lambda(a)+r}\left(\frac{k_{0}}{\xi}\right)^{(\lambda+r) / \gamma}\left[\frac{\log \left(k_{0} / \xi\right)}{\gamma}-\frac{1}{\lambda(a)+r}\right]-1
$$


Use the definition of $\Pi_{N I P}(a, \xi)$ to write the first order condition at a critical point as

$$
\lambda^{\prime}(a)\left(\Pi_{N I P}\left(a, \xi_{\alpha}\right)-R_{\alpha}\left(k_{0}\right)\right)\left[-t\left(\xi_{\alpha}\right)-\frac{1}{\lambda(a)+r}\right]=1 .
$$

The left-hand side is positive because $\lambda^{\prime}(a)<0$ and $k_{0}<\xi_{\alpha}$. It is not monotone though, either increasing or decreasing, which allows for the presence of more than one critical point. We are interested in critical points at which the second derivative is negative. We have

$$
\begin{gathered}
A(a) \frac{\partial^{2} \Pi_{N I P}}{\partial a^{2}}=\frac{\left(\lambda^{\prime}(a)\right)^{2}}{(\lambda(a)+r)^{2}}+\left[-t\left(\xi_{\alpha}\right)-\frac{1}{\lambda(a)+r}\right] \\
\quad \times\left[\frac{\lambda^{\prime \prime}(a)(\lambda(a)+r)-\left(\lambda^{\prime}(a)\right)^{2}}{\lambda(a)+r}+\frac{\left(\lambda^{\prime}(a)\right)^{2} t\left(\xi_{\alpha}\right)}{\gamma}\right]
\end{gathered}
$$

where $A(a)$ is positive at all values of $a$. The function $\lambda(a)$ was assumed decreasing and convex. Inspection of the right-hand side of this expression shows that, if it ever becomes negative, it will do so for values of $a$ that are relatively large. One can verify that this is certainly the case, for example, with the simple functional form $\lambda(a)=\lambda / a$. Hence, when many critical points exist, we should expect the maximizers to correspond to the highest valued among them.

The first order condition determining $a_{i p}$ contains an additional factor beside those computed for the case of $a_{\text {nip }}$. This additional element is 
the derivative, with respect to $a$, of

$$
O(a)=\int_{0}^{\infty} \lambda(a) e^{-(\lambda(a)+r) t} \max \left\{\mu\left(k_{0} e^{\gamma t}\right), 0\right\} d t
$$

One can check that

$$
O^{\prime}(a)=\int_{t=0}^{\infty}(1-t \lambda(a)) \lambda^{\prime}(a) e^{-(\lambda(a)+r) t} \max \left\{\mu\left(k_{0} e^{\gamma t}\right), 0\right\} d t
$$

does not have a constant sign. It is uniformly zero whenever $b$ is such that $\mu\left(k_{0} e^{\gamma t}\right) \leq 0$. When $\mu\left(k_{0} e^{\gamma t}\right)>0, O^{\prime}(a)$ is positive at low values of $a$ (high values of $\lambda(a)$ ), becoming negative as $a$ increases ( $\lambda$ decreases). The intuition is the following: at low values of $a, \lambda$ is large and the density $\lambda(a) e^{-\lambda(a) t}$ places a high probability to the Poisson event taking place early, that is, at low values of $t$. As we will soon show, the value of $\mu\left(k_{0} e^{\gamma t}\right)$ increases with time. Hence, at low values of $a$ the value of the option $O(a)$ is likely to be zero. As $a$ increases and $\lambda(a)$ decreases this shifts part of the distribution toward periods in which $\mu\left(k_{0} e^{\gamma t}\right)>0$, thereby increasing $O(a)$. In other words, an innovator who follows the IP strategy needs to buy time, via $a$, to allow $O(a)$ to increase its value, hence $O^{\prime}(a)>0$ initially. The first order condition determining $a_{i p}$ is therefore

$$
\lambda^{\prime}\left(a_{i p}\right)\left[\Pi_{I P}\left(a_{i p}\right)-R_{\alpha}\left(k_{0}\right)-O(a)\right]\left[-t(M)-\frac{1}{\lambda\left(a_{i p}\right)+r}\right]+O^{\prime}\left(a_{i p}\right)=1 .
$$


Considerations altogether analogous to those for the case of $a_{n i p}$ apply also in relation to the uniqueness of the critical values for $a_{i p}$, and the negative definiteness of $\partial^{2} \Pi_{I P} / \partial a^{2}$. 


\section{References}

[1] Anton, J. and D. A. Yao (1994), "Expropriation and Inventions: Appropriable Rents in the Absence of Property Rights," American Economic Review 84, 190-209.

[2] Anton, J. and D. A. Yao (2000), "Little Patents and Big Secrets: Managing Intellectual Property," Wharton School of Business, University of Pennsylvania.

[3] Battacharya, S. and J. R. Ritter (1983), "Innovation and Communication: Signaling with Partial Disclosure," Review of Economic Studies, 50, 331-46.

[4] Becker, G. (1971), Economic Theory, Knopf Publishing Co.

[5] Bessen, J. and E. Maskin (2000), "Sequential Innovation, Patents, Imitation." w.p. 00-01, Dept. of Economics, MIT.

[6] Boldrin, M. and D. Levine (1997), "Growth under Perfect Competition," UCLA and Universidad Carlos III de Madrid, October.

[7] Boldrin, M. and D. Levine (1999), "Perfectly Competitive Innovation," University of Minnesota and UCLA, November.

[8] Boldrin, M. and D.K. Levine (2002), "The Case Against Intellectual Property," The American Economic Review (Papers and Proceedings) 92, 209-212.

[9] Cohen, W.M., A. Arora, M. Ceccagnoli, A. Goto, A. Nagata, R. R. Nelson, J. P. Walsh (2002), "Patents: Their Effectiveness and Role," Carnegie-Mellon University.

[10] Horstmann, I., G. M. MacDonald and A. Slivinski (1985), "Patents as Information Transfer Mechanisms: To Patent or (Maybe) Not to Patent," Journal of Political Economy 93, 837-58. 
[11] Okuno-Fujiwara, A. Postlewaite and K. Suzumura (1990), "Strategic Information Revelation," Review of Economic Studies 57, 25-47.

[12] Ponce, C. (2003), "Knowledge Disclosure as Optimal Intellectual Property Protection," UCLA.

[13] Quah, D. (2002), “24/7 Competitive Innovation," mimeo, London School of Economics.

[14] Saijo, T. and T. Yamato (1999): "A Voluntary Participation Game with a Non-Excludable Public Good," Journal of Economic Theory 84, 227-242.

[15] Scotchmer, S. (2002), "The Political Economy of Intellectual Property Treaties," NBER Working Paper 9114.

[16] Scotchmer, S. (1991), "Standing on the Shoulders of Giants: Cumulative Research and the Patent Law," Journal of Economic Perspectives, 5, 29-41. 